\title{
Managerial Solutions for Debirocratization of Public Institutions
}

Valentin VEZETEU ${ }^{1}$

Abstract
In the category of ways of streamlining the management of any type of
organization, but especially of public institutions, the debirocratization is of particular
importance, along with the generalized promotion of strategic management, managerial
methodology, professionalization of managers and management or improvement of
organizational and managerial culture.
The attenuation of the degree of bureaucratization, internal and external, can
be achieved by promoting seemingly simplified managerial modalities, on which we will
focus in the present material. Either of these modalities must focus on reducing or
eliminating the causes that cause excess bureaucracy in the exercise of management.
In this way, the path opens up towards the computerization of the management
and execution processes, towards digitization. In this regard, Romania is far from the
level recorded by other European countries, especially Estonia, considered champion
in this regard. Without a professional management, no realistic scenario of
debocratization can be imagined. This is why the proposals advanced in the article are
of a managerial nature only, and those who must operationalize them are the managers
of these organizations.

Keywords: bureaucracy, management, managerial efficiency, professionalization, digitization

JEL classification: M10

DOI: $10.24818 /$ RMCI.2019.4.481

\section{Introduction}

Management is undoubtedly one of the most important factors for economic growth and development, which explains the different levels of efficiency of national economies. The amplification of its role requires, in turn, the promotion of managerial efficiency solutions at the macroeconomic and social level, as well as at the level of public and private organizations.

In the category of the modalities for improving the efficiency and the managerial efficiency are registered (Verboncu, 2019) as it follows:

- Generalized promotion of strategic management, in the sense of substantiating, elaborating, applying and evaluating realistic strategies;

- Managerial methodology, by promoting and using modern management tools and a set of managerial methodologies, general and specific;

\footnotetext{
${ }^{1}$ Valentin Vezeteu, The Academy of Economic Studies in Bucharest, valentinvezeteu@ yahoo.com, +40 (0) 765226363
} 
- Managerial reengineering;

- Improving organizational and managerial culture;

- Professionalization of managers and management, at all the organizational levels of economy and society;

- Depoliticizing the management of public organizations (public enterprises and institutions);

- Debirocratization of management.

Why are such solutions needed in the case of public organizations - public enterprises and public institutions? Because, in many respects, at their level, there are serious lags behind the state of managerial normality, because, in frequent situations, at their level the management exercised is defective. To such a status, excessive bureaucracy has an important contribution.

"Romania is recognized as a country in which the bureaucracy has seized control of most areas of activity (health system, legal system, education system, financial-banking system, etc.). At the moment, there is no Romanian public institution that lacks the bureaucratic system that is heavy and is generally felt in their administrative activity "(Frâncu, L.G., Hociung, G.I., 2012, p. 147). That is why, the last mode of managerial efficiency acquires a special significance in the economy of the steps towards increasing the degree of management involvement in the efficiency of organizations and the economy.

\section{Bureaucracy - brief theoretical considerations}

Bureaucracy is defined by the Explanatory Dictionary of the Romanian language (DEX, 1998) as "the interpretation and application of laws, provisions and regulations, etc." only in their letter, without the concern of understanding their spirit ". The term bureaucracy was first used by Monsenior de Gournay (1745) and comes from two words in two different languages: the French "bureau" and the Greek "kratos". The initial meaning was, in essence, that of "rules of the office", that is, of the officials. The power of these officials has been signaled on numerous occasions, long before the bureaucracy becomes the subject of scientific analysis. For example, in the nineteenth century, Honore de Balzac (1799 - 1850) defined perhaps the most plastic bureaucracy, as representing the "power of the giants in the hand of the pygmies" and, in a way, this is the meaning that the bureaucracy retained until today (see also www.rasfoiesc.com/education/ /Organization-social-si-birocracy).

The specialists insist on two acceptances of bureaucracy: a pejorative one, considered the first acceptance of the word, used since the eighteenth century, an acceptance to which we refer even today, when we insist on "reducing bureaucracy"; a second, truly scientific, acceptance has a normative dimension.

At the same time, approached from inside or outside the organization, the bureaucracy can be internal and external, each of them with different forms of manifestation. 
The specialists identified (Jianu, 2009) several characteristics of bureaucracy in public institutions, developing Weber's conception in this field. Thus, the following can be identified as more important:

- Specialization through a clear division of labor

We mention here that, both at the level of companies and at the level of public institutions, the functional specialization at compartmental level and even at the position level is one of the defining characteristics of the hierarchicallyfunctional organizational structures specific to medium and large size organizations. Functional specialization, a result of the division of labor, makes each occupant a specialist in performing the tasks assigned to him and, at the same time, offers little chance for him to evolve as well in a position with different tasks, competences and responsibilities.

- Authoritarian hierarchical structure, in an organization the functions are ordered according to the principles of hierarchy and the levels of graded authority

Such a feature is highly visible in the case of special ministries, where the specific management style is of the military, military type, the hierarchies are clear, visible, and the predominant organizational relationships are those of the authoritarian, hierarchical type, that is, of direct subordination. At the same time, we are witnessing the overpopulation of some compartments with staff, without adequate coverage in the tasks to be exercised (we refer not only to civil servants, but also to contract staff within public institutions and beyond).

- The system of formal rules and regulations, the bureaucratic organizations accepting "the rules regarding the coercive, physical, priestly or other means available to the officials"

The functioning of public institutions with obvious bureaucratic management is marked by well-defined and respected formal rules and other regulations, sometimes even elements of managerial methodology, such as the procedures used in exercising work processes, being so strict that they often turn them into closed organizations, hardly accessible to dialogue. The tendency to "move" the papers from one compartment to another, from one station to another, without any justification, is obvious.

- Impersonality and impartiality, the authority being dependent on the rules of the organization, impersonal and corresponding to the hierarchical level of a person;

- Career promotion follows, in turn, the rule of seniority and proven competence in the activity

At least theoretically, as a rule, the promotion is done according to age and competence (knowledge, qualities and professional or managerial skills). Competence is another condition that must be fulfilled, usually to shorten the time period required by moving to a higher degree (special ministries) or to a higher 
position as a function. The main problem that arises in this context: who and how does the appreciation of a special competence that allows the advance before the deadline or the normal advance? characteristics.

- The efficiency of the organization results only from observing these

These characteristics, specific to the Webberian model of bureaucracy, simply idealize it. Reality rejects such a theory, precisely because of the malfunctions that it generates in the functional plane and in the one of efficiency and effectiveness.

As for the dysfunctionalities, the specialists (www.scritub.com/ sociologie/teorii-clasice-despre-organizatii) insist on the following aspects: the decision-making process is affected by the hierarchical chain and can be undermined by modifying the information; dilution of responsibility; the emergence of informal structures that undermine the formal structure; excessive rigidity; neglecting the informal structure; does not realize the full exploitation of human resources due to lack of confidence and fear of coercive means. All this ultimately translates into inefficiency in the use of resources and in the inappropriate application of the legislation.

Bureaucracy also has its advantages. Among them, strict specialization (with immediate impact on efficiency, accuracy and quality in problem solving) and impartiality in interpersonal relationships, which determine the justice of decision-making, promoting competence and eliminating subjectivism, are the most significant.

Bureaucracy generates a particular type of management, called bureaucratic management. In public administration, the objectives are rather social, and the principles underlying the functioning of public institutions are partially different from those in private organizations, focused on maximizing profit. Bureaucratic management is "the method applied in the management of administrative affairs whose result has no money value on the market. Its value cannot be evaluated in a market transaction and, consequently, it cannot be expressed in monetary terms. "(Ludwig von Mises, 2003). In turn, bureaucracy is a major public management dysfunction.

\section{Bureaucratization of public institutions - a causal approach}

The excessive bureaucracy of public institutions, addressed both as internal bureaucracy and in relation to the citizen (external bureaucracy), is a consequence of exercising unprofessional management at the level of these categories of organizations. The main causes of manifestation of this major dysfunctionality refer to:

- The questionable professionalism of a large number of managers in the upper echelon of the organizational structure of some ministries, departments, national agencies / authorities or public institutions, which are in managerial

$484 \quad$ Volume 20, Issue 4, October 2019 Review of International Comparative Management 
positions on political criteria and less on the basis of professional and managerial competence (manifesting Peter's principle is visible in many public entities).

- The tendency to multiply the number of management and execution positions, generated by the multiplication of tasks and not by the volume, complexity and difficulty of their objectives (in this context, it is visible the manifestation of "Parkinson's laws", of "multiplication of work", respectively "multiplication of subordinates").

- Both managers and executives (civil servants or contract staff) do not have the habit of working on objectives (decentralization, cascading of objectives within organizations is a less common managerial practice); hence the tendency of evaluating / appreciating the performance of the staff according to the principle "the manner of accomplishing the tasks" and not according to the "degree of achievement of the objectives".

- Poor communication between the organizational subdivisions of the same public institutions or between institutions, including at the governmental level, with unfavorable consequences on the quality of the decisions taken (the scientific basis and the opportunity are the most affected qualitative parameters).

- Fluffy legislation, sometimes ambiguous, unstable, doubled by the excess of procedures, mandatory to be respected by managers and executives. Even if the promotion of procedures, system or operational, is subject to the management methodology, we consider that their rigid application limits the decision-making and operational autonomy of those who run and manage their public institutions or organizational subdivisions, as well as of the executors. Moreover, we consider that the use of procedures has received exaggerated accents. This is the cause of bureaucratic amplification in both the front office and back office.

- Multiplication of the number of documents (informational situations or simply papers), requested to the citizen who addresses the public institution for solving a problem; The "paper cutting commission" set up in 2016 does not seem to have achieved the success expected by everyone, namely the reduction of the number of documents requested to the citizen and, implicitly, the desired debirocratization. The "areas" most exposed from this point of view are those specific to public procurement and access to European funds.

- The low degree of computerization of the processes of management and execution in public institutions, of digitization of the public administration. Egovernment solutions, namely the use by the public sector of information and communication technologies in order to improve the provision of information and services by encouraging citizens' participation in the decision-making process and making government accountable in a transparent and efficient way, is at a reduced level, despite a growth trend, registered in recent years. From this point of view, our country is in a leading position (with a DESI index - Digital Economy and Society Index - of $33.21 \%$ in 2017) in terms of: connectivity - coverage, speed, costs (22nd place) of 28); human capital - percentage of Internet users, basic IT skills, employees in the field (last place); how to use the Internet - information, relaxation, banking, shopping, social networks (last place); integration of digital 
technology - exchange of information between companies, electronic invoices, cloud services, online shops (last place); digital public services - 6\% of Internet users access e-government solutions, only $63 \%$ of the data published by the Government are online. In this regard, Estonia occupies the first position, offering, by far, an experience worthy of consideration.

- Poor digital culture of the majority of the population.

\section{Managerial solutions for the debirocratization of public institutions}

We propose, below, some solutions of debirocratization of public institutions, specifying that they can be extended to other categories of organizations (especially public enterprises, focused on providing services for citizens).

- The first solution: the reengineering of the management, after a preliminary diagnosis of the managerial viability of the organizations with high degree of bureaucracy. The methodology to be operationalized comprises several distinct sequences, such as: objectives, processes, structures, people (managers and executives), results (Verboncu, 2018). If the objectives are taken from the strategy and the policies redesigned for its operationalization, the remodeling process is more difficult, the rethinking and redesign of processes that effectively support the achievement of the objectives. The structural-organizational redesign succeeds the procedural remodeling and involves the resizing of the number of positions, functions and compartments, flattening the organizational structure by reducing the number of hierarchical levels and reconsidering the organizational relationships by amplifying the functional relationships, as well as those of cooperation. The procedural remodeling and the structural-organizational redesign have a major impact on the organizational flexibility and provide the necessary premises for the considerable reduction of bureaucracy. If the positions will be provided with competent personnel, then the chances of success in this area will increase. That is why it is necessary to reconsider the role of human resources management, especially regarding the activities of selection, recruitment, hiring and promotion of the managerial and execution personnel; in other words, the exercise of these activities must focus on the competence of those who participate in competitions for occupying management and execution positions, regardless of whether they do so in the case of civil servants or contract staff. It is assumed that only competent people can learn and apply the content of specific methodological elements (mainly procedures and standards), eliminating ambiguity in this area. Important attention should be paid to the organization and conduct of competitions for the management positions, whereby the knowledge, qualities and managerial skills should be tested, not the legal knowledge, as is the case in most cases, at present.

The redesign of the management of public institutions also involves the redesign of its informational component, with emphasis on improving the quality of information, resizing information circuits / flows and using sophisticated information procedures. A fundamental aspect that marks the redesign of this 
component of the management is the satisfaction, by the information system, of the information needs of the beneficiaries of information, respectively the managers and executors located in different hierarchical positions.

The achievement of this objective requires the determination of the information needs or needs of the potential beneficiaries, depending on their job descriptions, which mainly contain the individual objectives, tasks, competences and responsibilities that support such objectives. The individual objectives demand the carrying out of some work processes called tasks, and their exercise implies a certain decision-making freedom of the occupier (competences). These are translated by the decisions of the incumbent, whose foundation requires quality information, in the volume and structure requested by the decision maker. These really represent the "information needs", any additional amount of information provided to the job holder (especially the management), causing the unjustified loading of the time budget, being practically unusable in substantiating and adopting decisions or initiating actions. Hence the need to promote and use the dashboard, as a management role with a dual role: to rationalize the information system and to make time management more efficient for managers.

- The second solution: promoting a systemic approach to objectives, which includes the fundamental objectives (at the organizational level), the derived objectives (at the level of functions / activities and, implicitly, the departments), specific objectives (associated with the tasks and functional/operational compartments) and, very important, the individual objectives, at the level of management and execution positions. From this perspective, the use of the job description as a management tool and not just as an organizational document is a priority. Within it, one must find the individual objectives, derived from the specific ones, together with the support elements necessary for their fulfillment (tasks, competences, responsibilities), delimited and dimensioned so as to respect the "golden triangle" of the organization, respectively the balance quantitative between tasks, competences and responsibilities throughout the existence of the position (Nicolescu, 2011). The objectives are the quantified and / or qualitative expression of the purpose for which the organization or a process / structural component of it was founded and works. At the level of public institutions, the most common mistakes encountered in setting objectives refer to: the confusion between attributions / tasks and objectives, the most edifying evidence being found in job descriptions, where there is no adequate delimitation between these notions, in the sense that the objectives are expressed through attributions or tasks; the objectives set out in the job descriptions do not fully comply with the recommendations regarding the SMART characteristics that they must possess (in many cases they are not measurable, they are not realistic and they are not framed in time; finally, a true cascade of the objectives cannot be invoked from top to bottom, from the fundamental objectives to the individual objectives. Let us not forget that the objectives are the most important means of individual and group responsibility, alltogether with their decisive role in the printing of certain characteristics of order, discipline and rigor in the exercise of work processes 
- The third solution: promoting efficient mechanisms for the functioning of the positions, focused on the correlation between the official authority confined to the positions and the personal authority of the holders of positions; in other words, the professional exercise of management and execution positions requires the compatibility of the occupants with them through competence. It is common practice to set up positions to meet some human demands, not to ensure the proper exercise of processes called "tasks" and, implicitly, to ensure the fulfillment of individual objectives. This was achieved by the over 1.2 million budgeters, by the multiplication of the number of public institutions or by the dimensional amplification of them, all being reliable sources for the excess of bureaucracy. We are convinced that, if a diagnosis of the public administration were to be made, there would be many positions whose existence is not justified. Their occupants, mainly civil servants, do nothing but "produce paper", which is largely unnecessary, which burdens the information system and delays the resolution of some problems.

- The fourth solution: promoting a true "document management"; the avalanche of papers of all kinds, some justified, others just to justify the inability of some employees to solve their tasks, calls for amplification and intensification of the "paper cutting" action started in 2016, together with a real redesign of the content of those who are considered useful. Document management has two major objectives: streamlining internal processes in public institutions and streamlining relationships with citizens. The achievement of these objectives, in the sense of debirocratization, involves the approach of document management in close connection with the digitization. From this perspective, the rationality of document management ensures, simultaneously: the increase of labor productivity, the reduction of costs, the uniform access to information, the rapid access to information, the management of all categories of information, the adequate visualization of them and the mitigation of risks.

- The fifth solution: digitization, respectively, increasing the degree of computerization of the activities of the public institution by promoting integrated IT applications; such a solution takes into account the still very low degree of electronic processing of information, against the background of the reluctance of some employees to use the computer in the exercise of tasks (fear of job loss). In a broader sense, this major way of substantially mitigating bureaucracy is called "digitization", an area in which, as we have mentioned, Romania occupies the last position between the countries of the European Union. Paradoxically, Romania has an IT domain appreciated in Europe, but it is at the bottom of the ranking of the EU countries in terms of digitization!

The digitization ensures the increase of the transparency of the decision of the public administration, according to Law 52 of 2003, in the sense of facilitating the participation of the citizens in the elaboration of the normative acts and their involvement in the adoption of the decisions.

- The sixth solution: stability and consistency in the application of the legislation; for this it is necessary to eliminate the legislative chaos that regulates

$488 \quad$ Volume 20, Issue 4, October 2019 Review of International Comparative Management 
the functioning of the institution and the relations with the citizens, efforts of cleaning the legislation and of a unitary approach of the normative provisions.

The effects of operating these solutions will be found both at the level of public administration, as well as at the level of citizens and the business environment; these are reflected in:

- appreciable time savings for citizens (eliminating the "waiting" in queues);

- $\quad$ stress reduction;

- eliminating the dependency of solving a problem on the counter program to which the citizen should come;

- the means of information and interaction are diversified;

- increases the productivity of the work of the public administration;

- the costs with the issued papers are considerably reduced;

- informing the citizen "in real time" and, in general, of those interested (the business environment) about the stage of solving some problems, the legislative news etc.

The public administration will indeed be a smart one, as most of the big time-consuming problems will be solved quickly, transparently and efficiently.

\section{Conclusions}

The aspects presented in this material are a true alarm for macro and microeconomic and social decision makers from at least two points of view: first, the bureaucracy beyond the normal limits is very resource-consuming; second, Romania is a country of the European Union which, although it has spectacular programs, does nothing in terms of digitization, proving the last position in this chapter. In many areas of public administration, health, education, the judicial system and so on it works like 50-60 years ago!

The excess of bureaucracy must be stopped, as long as we have smart solutions, as alternatives in solving the problems we face, from setting up companies to civil status documents, from paying taxes and taxes to auto documents.

None of the methods of managerial efficiency will have effect if we do not have professional managers; we recommend, as a priority, to carry out diagnostic studies of managerial viability in order to detect causally the main strengths and weaknesses, of the viability potential of the led and managed organization. If they find that the excess of bureaucracy visibly marks the functionality of the organization, then they must proceed to the careful analysis of the proposed debirocratization solutions and, depending on the constructive and functional particularities of the management system, to try their partial or full operationalization. 


\section{References}

1. Nicolescu, O., coordinator (2011) - Dictionary of management, Pro-university publishing house, Bucharest

2. Verboncu, I. (2019) - The organization's management in 360 questions and answers commented, University Publishing House, Bucharest

3. Verboncu, I. (2018) - How do we lead? Between amateurism and professionalism, University Publishing House, Bucharest

4. Jianu, Al. (2009) - Considerations on bureaucracy, Constantin Brâncuși University, Tg. Jiu, Series of Letters and Social Sciences, no.1 / 2009

5. Frâncu, L.G., Hociung, G.I. (2012) - Bureaucracy in the current economic context, in Theoretical and Applied Economics, no. 6 (671)

6. Radu, L. (2002) - The evolution of administrative systems (I), in the Transylvanian Journal of Administrative Sciences, no. 1 (7) / 2002

7. Mises, L. Von (2003) - Bureaucracy, Ludwig von Mises Institute

8. www.scritub.com/sociologie/teorii-clasice-despre-organizatii

9. www.rasfoiesc.com/educație//Organizarea-sociala-si-birocratia

$490 \quad$ Volume 20, Issue 4, October 2019 Review of International Comparative Management 